\title{
The Taste of the Japanese Courtyard Space Design under the Zen Thought
}

\author{
Xin $\operatorname{Bian}^{1}$ \\ Shandong Women's College \\ Jinan, China \\ e-mail:155051477@qq.com
}

\author{
Yuan Chen ${ }^{2}$ \\ Shandong Women's College \\ Jinan, China \\ e-mail: zy_wlh@126.com
}

\begin{abstract}
After Buddhism was introduced into Japan, it had an extremely profound influence on the culture of Japan, among the many sects of Buddhism in China, Zen thought influenced Japanese gardening art most. This paper revealed the spiritual source of the Japanese garden design through the analysis of the characteristics of Zen thought, its development in Japanese and the thought's influence and continuity on Japanese landscape garden and tea garden.
\end{abstract} design

Keywords-component; Zen thoughtg; Japan; courtyard

\section{THE CHARACTERISTICS OF ZEN THOUGHT}

Ancient China's religious thought was made up of Zen, Taoism, Confucianism together, Zen was a religious thought combined with Chinese local culture after Buddhism entered into China. Zen thought underwent a rapid development in the Tang Dynasty, in addition to have a great influence on Chinese culture, it also deeply affected Japanese culture, art, aesthetic taste, etc. Zen thought advocated that through the way of thinking of meditation and intuitive experience, you could achieve spiritual transcendence and freedom. Zen thought believed that "people are in the universe, and the universe was also in the minds of people. The relationship between human and nature was not only involved in each other, but also they were a whole like one object." The key to achieve this realm was inner experience, because all things in the universe were born out of people's heart. And the characteristics of Zen thought was summarized as follows:
A. Zen thought advocated directly pointing to the soul of man, DanDangZhiRu, experiencing the quiet nature, and sight of nature to achieve Buddha.

B. Zen affirmed the rationality of real life, avoided reject real life like other sects, such as Buddhism. Zen believed that the realistic daily life was the reveal of human nature, it advocated to find the nature of quiet in ordinary life, and experiences the artistic conception of Zen, realized the spiritual transcendence.

C. In addition to inherit the Buddhism thought, Zen thought was also combined with the inherent thought of middle earth, it continued to innovate unceasingly, advocated method beyond reality, denied the transcendence beyond real life of "wander out of the dirt", the purpose was to realize the psychological, conceptional and emotional transcendence in sentient life.

Compared to other countries in the world, Japan's rising popularity for Zen is out-of-the-way, because Japan doesn't just admire the advanced Chinese culture, it is also owing to Japan's own factors. Japan is a country near the sea and far away from the mainland with oceanic climate significantly, typhoon, tsunami and earthquake happens there frequently, because these natural disasters occurs frequently, it makes Japanese admire infinite power brought by nature greatly and deeply realize the tininess of their own lives, and the sense of impermanence penetrates into the aesthetic consciousness of the Japanese nation, which leads to a desire to transcend and release, it is the desire that makes Zen thought met with Japanese aesthetic consciousness.

\section{THE COMBINATION OF ZEN THOUGHT AND JAPANESE ROCK GARDEN}

In the middle of Japanese muromachi period, zen thought gradually began to affect the Japanese garden art creation. Zen thought purely advocated to depend on the awareness of inner heart, excluding all the speech, writing and the ways behavioral expression to sublimate Japan's landscape design and creation to subjective idealism getting rid of all the material conditions. As a result, the designers, that was the monks of the temple, built the temple garden by extremely concise technique with very pure, simple, plain stuff. The 
design of the temple garden highlighted quiet and harmony of the broad nature and religion world, let people achieve the deep feeling of the religious realm through introspection and sitting quietly .In the Muromachi period, Japanese rock garden design exerted the zen thought " Vatican and self", advocating freedom, mind peaceful realm to an extreme, promoted the zen thought to the zenith.

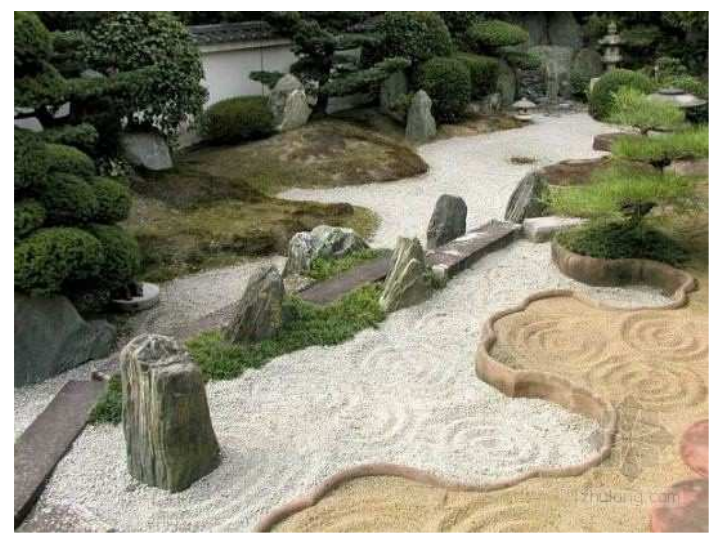

Figure 1. Japanese rock garden

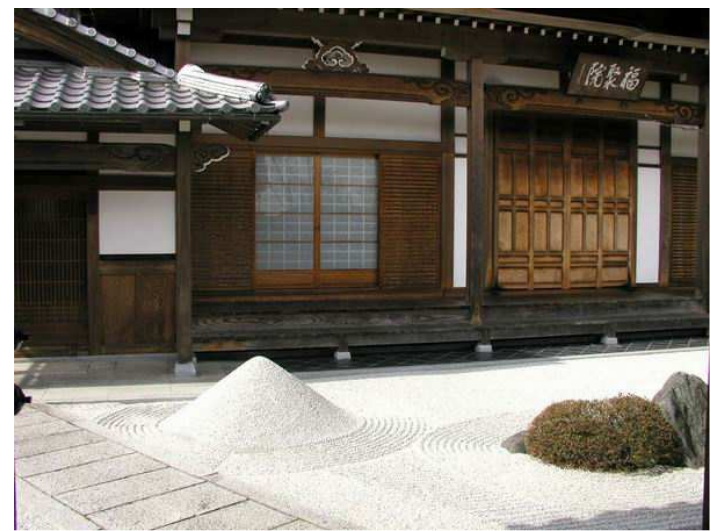

Figure 2. Japanese rock garden

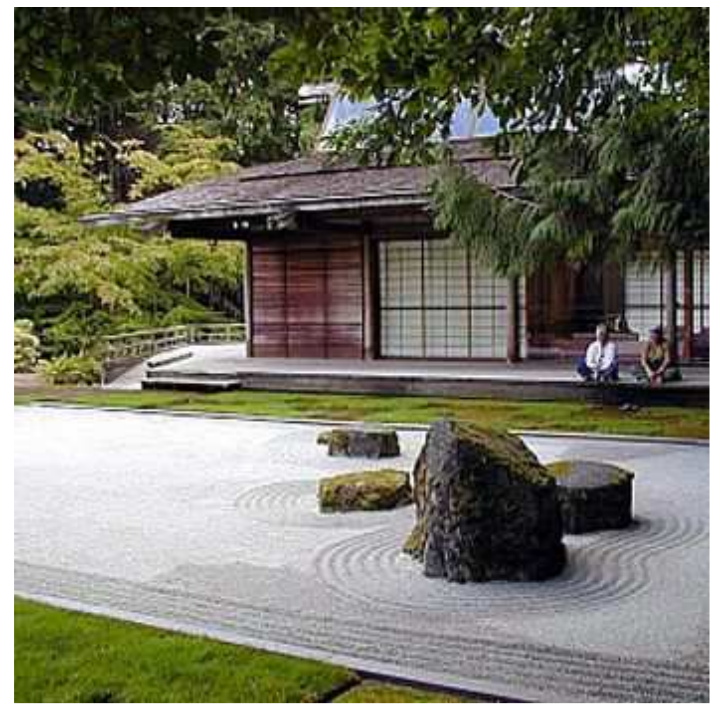

Figure 3. Japanese rock garden
The so-called Japanese rock garden refers to not to take water as element in the garden design, but mainly use various forms of hill stones, stones to represent the islands, rocks, peaks etc; and lay out flashing water ripple with white sand, on this account to express the all kinds of capricious landscapes such as rivers and lakes, waterfalls, brooks, etc.( Fig.1, Fig.2) There are usual a number of evergreen trees such as pines and cypresses coupled with some shrubs., flowers plants, or don't have any plants, selective plants are relatively short and small, every plant is carefully selected, trimmed, controlling the shape of the trees and keeping the required forms (Fig.4). In the Japanese rock garden, the stones chosen are also different, which are often relatively vigorous and slightly large in shape, the design combination modes are also different, generally choose more powerful stone which shape is slightly big, design combination is different too, do not usually choose folded method, appearing in group or alone by combination mode or ornament type, form annulus with the bottom of white corset stones, forming the bending curve, like terrifying waves, running mountains high (Fig.3) The design style of the entire courtyard is uniform, is a form of dwelling on the natural landscape, to show the aesthetic thought of zen thought. The technique and material selection of Japanese rock garden are relatively very pure and natural, the choice of stone, white sand highlight that, but because of a lot of design, dermatoglyphic pattern are decorated by white sand, so it is difficult to fix, so the landscape form, only to be enjoyed in the room for people.(Fig.5, Fig.6) so Japanese rock garden is not generally very big, it can only be regarded as a courtyard. Like the big fairy courtyard in daitoku-ji temple in Tokyo, which is a Japanese rock garden with small area of only ninety-nine square. Main feature is in the north of the courtyard, in the courtyard of the northeast corner designing a piece of form mountain stone, in the middle laying a cascading waterfall with white sands. The waterfall make a stream in place of delivery port, a stone across the stream, which became a bridge...Walking in it, it's abstract, pure, good giving people various daydream space. Thus Japanese rock garden fantastically convert a few elements to the grand scenery such as beautiful mountains and rivers and big waterfalls in the sky. Zooming the beautiful scenery, an analog technique of the simulation and creation of nature scene are applied to the landscape design, this kind of artistic conception is likely simple, but fascinated, making Chinese zen culture show in gardening art, opening up a new chapter of the Japanese garden design with the combination of zen art.

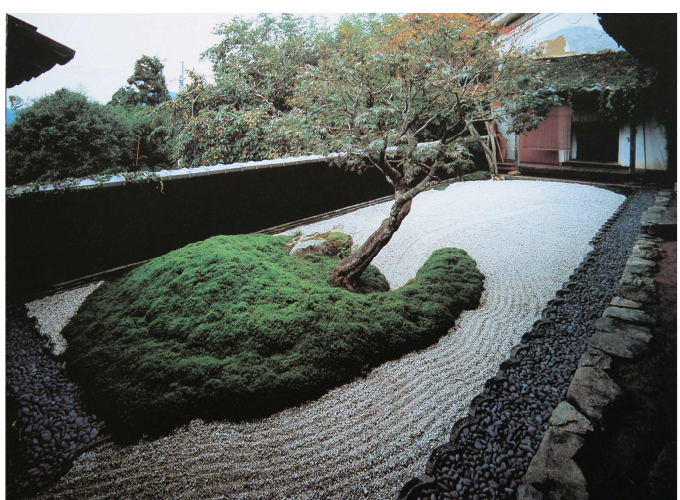

Figure 4. Japanese rock garden 


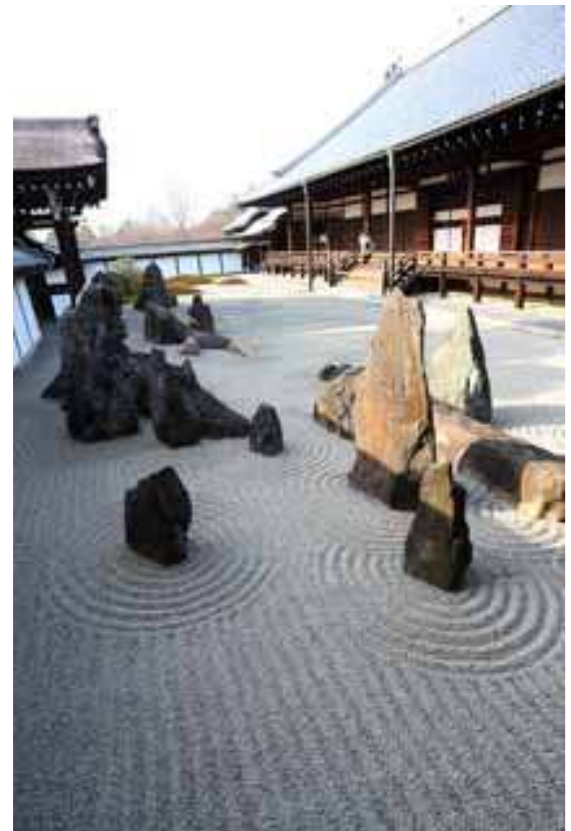

Figure 5. Japanese rock garden

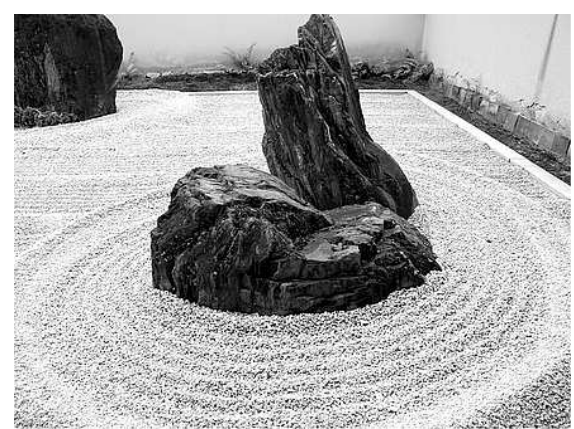

Figure 6. Japanese rock garden

\section{THE COMBINATION OF ZEN THOUGHT AND JAPANESE TEA GARDEN}

The cultural thought of Zen not only spread in the landscape design, but also had a deep profound influence on Japanese tea garden design. The tea ceremony has been the traditional art skills in Japan since the ancient times, tea culture originated in China, but it has always been popular among Japanese, it could not only be a mean of communication, but also could edify sentiment and refreshing people's heart. Tea culture was the continuation of " Gentry Culture" for two thousand years, "Gentry Culture"was composed of piano, chess, calligraphy, painting, tea, wine, YaShe, garden, antique, etc. In Tang Dynasty, gentry had ambition and intelligentsia began to PingMing, according to the record in "the Tea Saint", Bai Juyi had ever SiZhuXianLe, HengChaPingMing in garden.

The tea leaf was introduced into Jap from the end of the Han Dynasty, tea wasn't popular in Japan until the Song Dynasty when Buddhism and the tea custom of Zen was introduced. In medieval muromachi period, drinking tea gradually developed into an art in Japan. Tea drinker regarded Zen thought as the leading, judging the behavior of drinking tea, blended in the reclusive thought of "Gentry Culture" at the same time, developed the tea ceremony spirit into inner cultivation, and cultivated people's virtue of comity and humility. Rush development of tea ceremony in Japan's made the Japanese garden add a new type of garden-tea garden.(Fig.7)

Tea gardens were different from other types of landscape design, the garden had many stone arrangement for the purpose of sitting, rest, squatting, washing hands and other practical utility. There wasn't much rockscape. In addition to water bowl made by stone, which was used to wash hands and gargling for the guest, there was stone lamp lighting at night, there wouldn't be other featured landscape in it.( Fig.8, Fig. 9) Evergreen trees were along the road, there were planting method such as freestyle planting, clump planting and solitary planting. Grass or bryophytes were chosen as ground cover. In order not to disturb the quiet of the people, in addition to the plum blossom, there was not any other ornamental flowers. In design, the road was laid with grass on both sides, and there was "FeiBai" (a type of white space in the traditional Chinese painting techniques) left on the road out of natural interest. Using "wooden door" as entrance door, and using bamboo fence as bounding wall. All of these depicted a peaceful and beautiful sight.

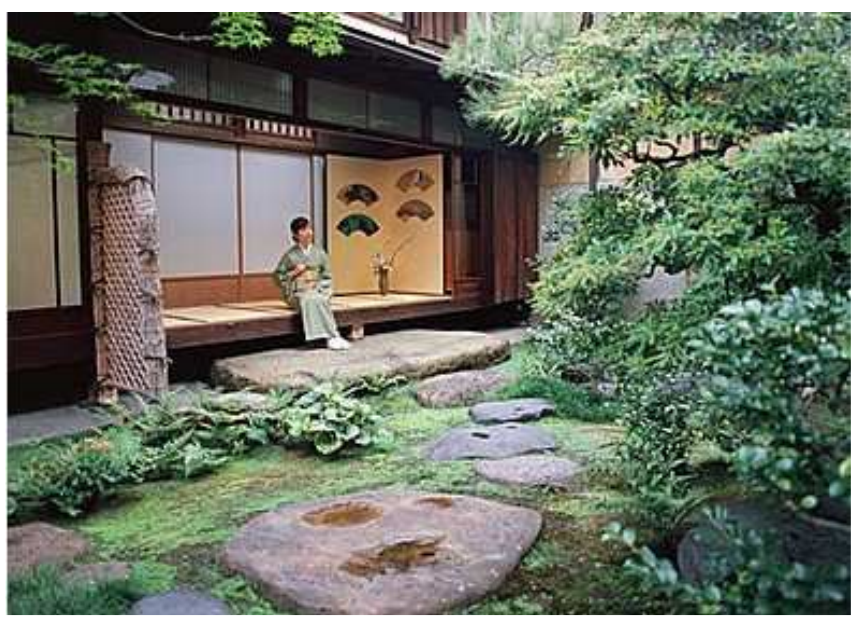

Figure 7. Japanese tea garden

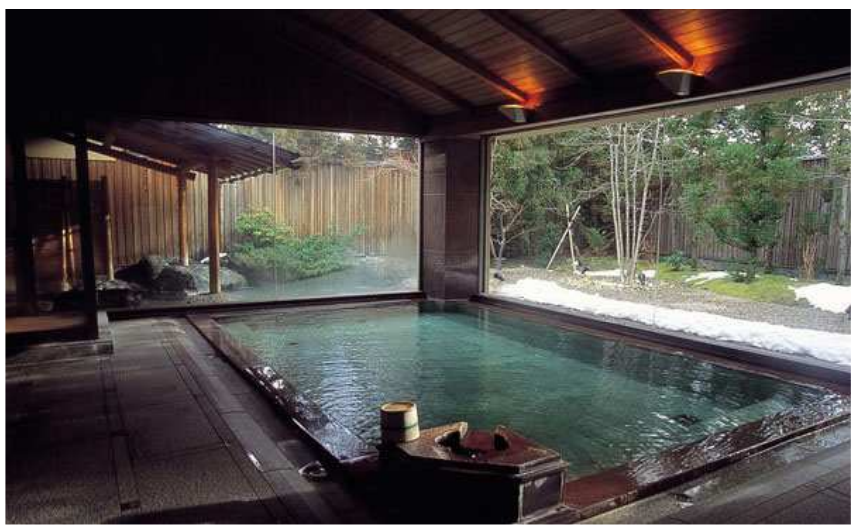

Figure 8. Japanese tea garden 
The style of Tea garden is simple and the Layout has been designed in full accordance with the tea ceremony, which highlights the insipid and comfortable state of the Zen. Tea garden consists of two parts, "outdoor courtyard" and "inside courtyard", which is separated by "middle gateway". When a guest comes here, he would wait at the outdoor corridor of "outdoor courtyard" first, and then walk along the gravel path to "middle gateway". The host usually waits for the guests at "middle gateway", leads the guest to the inside corridor of "inside courtyard". The guest should clean his clothes and change his shoes for politeness, then scoop up water in stone stoup by bamboo spoon to Wash his hands and gargle, in order to put down evil things and eliminate disasters. After that, the guest would enter the tearoom. There is a well in the courtyard of Tea garden, specifically for making tea and washing. Generally speaking, a dry creek will be set up paved with broken stones and white sand in the Tea garden, and "outdoor courtyard" and "inside courtyard" are connected by a bridge over the dry creek.

Tea garden of Japan is plain and unflashy in design, holds dear nature, and stands close to nature, which is full of natural pleasure. The design adopts the way of Zen thought that body and mind perceive, and bring people into a light, quiet, beautiful detached secular realm which has a quality suggestive of poetry or painting. Zen thought makes ideas and mind sublimated, brings people into the "Zen" realm, besides the abundant landscape and performance techniques in Tea garden, the Sentiment and artistic conception of which is further more than vivid reality of these landscape.

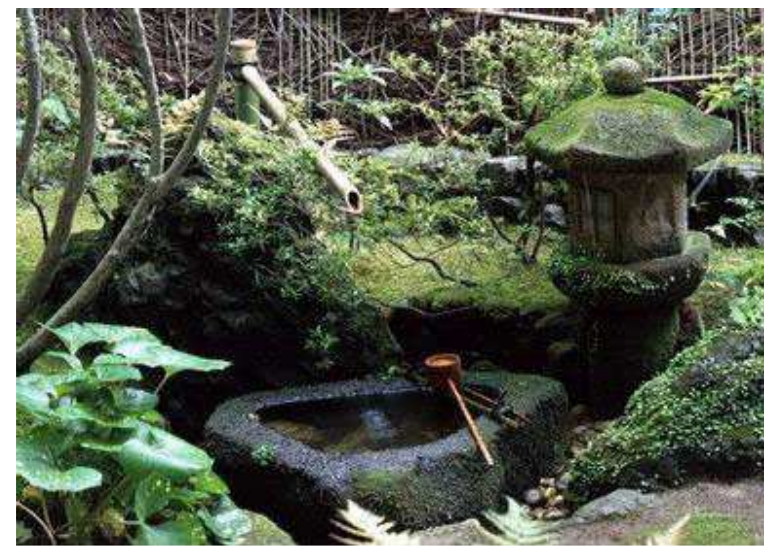

Figure 9. Japanese tea garden

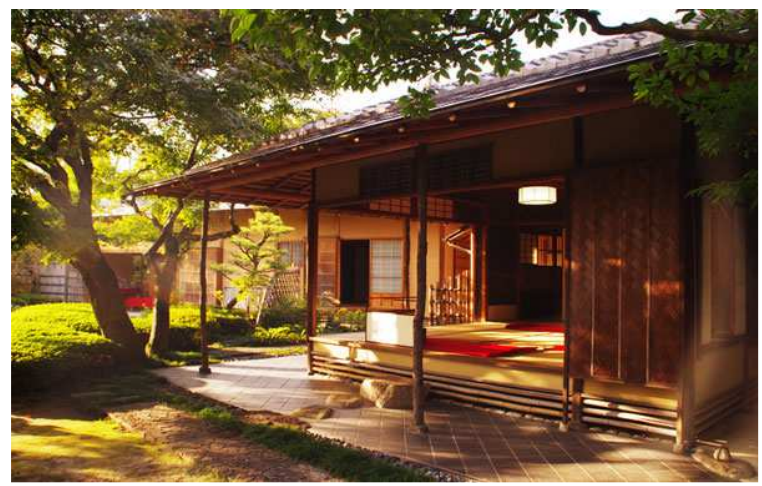

Figure 10. Japanese tea garden
From Japanese rock garden to the Tea garden, we will find, Japan has been developing toward religionization and nationalization on the basis of absorbing Chinese garden art, finally creates significant and valuable impressionistic garden all her own, a integration of natural beauty, a representation closer to nature. It can be said it is the continuation of the religious thought, more precisely, it is the promotion of aesthetic ideas, and all of these depend on the emotion and close relationship of The Japanese nation to Zen culture.( Fig.10)

\section{CONCLUSION}

The area of Japanese land is relatively smaller than other countries, so exotic Landscape is scarce. From ancient Japan, the people enjoy and appreciate the beauty of nature, focus on details, and harbor boundless admiration and appreciation of beauty and non-living objects. On the other hand, because Buddhism in Japan is very popular, and it holds that nature is a transcendent, therefore, the Japanese garden naturally has a strong religious color. So, many Japanese gardens are named as "Monks Park" or " Religion Garden ", and so on.

Zen thought has profound impact on Japanese garden imperceptibly. the Japanese culture Japanese has formed a style which is enduring for a long time. Although the Zen originates from china, it has undergone the integration and variation of the spirit and culture of Japanese nationality, has become the dominant culture of Japan, has been an important part that can't be missed, and now there is nothing much more that can represent Japanese culture than Zen thought.

\section{REFERENCES}

[1] Xia min. Oriental spirit in Ando Tadao's recent works [J]. New construction, 1988 (2): 27-29

[2] Shen Zhaohui. Ando Tadao. The source of the spirit of Architecture the Zen thought [J].The era of the building, 1999 (1): 92-94

[3] Zheng Wei, Chen Yuzhen. Water management and contemporary architecture in Japan [J]. Huazhong architecture, 1999 (2): 22-23

[4] Zhang Shinian, gardening and planting: characteristics and comparison of Chinese and Japanese ancient plant landscape [J]. Huazhong architecture, 1994 (1): 43-45

[5] Du Shunbao, China garden [M]. Beijing: People's publishing house, 1997

[6] Zhang Junhua, inner garden - the Japanese traditional garden art [M]. Kunming: Yunnan University press, 1999.

[7] Liutuo, garden art appreciation [M]. Taiyuan: Shanxi Education Press, 1997.

[8] Hong Xiuping, Wu Yonghe, metaphysics and Zen [M]. Hangzhou: Zhejiang people's publishing house, 1992.

[9] Daisetz Suzuki, the ideological system of modern Japan [M]. Japan Zhu Mo study, 1965.

[10] Daisetz Suzuki, Zen and Japanese culture [M]. Shanghai, Shanghai Joint Publishing Company, 1989. 